\title{
Corrigendum
}

\section{Corrigendum to "Outcome of Rhabdomyosarcoma in First Year of Life: Children's Cancer Hospital 57357 Egypt”}

\author{
Enas El Nadi, ${ }^{1,2}$ Emad A. H. Moussa, ${ }^{1}$ Wael Zekri, ${ }^{1}$ Hala Taha, ${ }^{3}$ Alaa Yones, ${ }^{4}$ \\ Mohamed Saad Zaghloul, ${ }^{5}$ Madeeha El Wakeel, ${ }^{6}$ and Rania M. Labib ${ }^{7}$ \\ ${ }^{1}$ Department of Pediatric Hematology/Oncology, Children's Cancer Hospital Egypt 57357 (CCHE), 1 Seket El-Emam, \\ Sayeda Zeinab, Cairo 11441, Egypt \\ ${ }^{2}$ Faculty of Medicine, Beni Suef University, Beni Suef 62511, Egypt \\ ${ }^{3}$ Departmrent of Surgical Pathology, Children's Cancer Hospital Egypt 57357 (CCHE), 1 Seket El-Emam, \\ Sayeda Zeinab, Cairo 11441, Egypt \\ ${ }^{4}$ Department of Surgery, Children's Cancer Hospital Egypt 57357 (CCHE), 1 Seket El-Emam, Sayeda Zeinab, Cairo 11441, Egypt \\ ${ }^{5}$ Department of Radiotherapy, Children's Cancer Hospital Egypt 57357 (CCHE), 1 Seket El-Emam, Sayeda Zeinab, Cairo 11441, Egypt \\ ${ }^{6}$ Department of Radiodiagnosis, Children's Cancer Hospital Egypt 57357 (CCHE), 1 Seket El-Emam, Sayeda Zeinab, Cairo 11441, Egypt \\ ${ }^{7}$ Department of Research, Children's Cancer Hospital Egypt 57357 (CCHE), 1 Seket El-Emam, Sayeda Zeinab, Cairo 11441, Egypt
}

Correspondence should be addressed to Enas El Nadi; elnadienas@gmail.com

Received 12 July 2015; Accepted 2 September 2015

Copyright (C) 2015 Enas El Nadi et al. This is an open access article distributed under the Creative Commons Attribution License, which permits unrestricted use, distribution, and reproduction in any medium, provided the original work is properly cited.

In the paper titled "Outcome of Rhabdomyosarcoma in First Year of Life: Children’s Cancer Hospital 57357 Egypt” [1], Enas El Nadi has an additional affiliation and it is added here.

\section{References}

[1] E. El Nadi, E. A. H. Moussa, W. Zekri et al., "Outcome of rhabdomyosarcoma in first year of life: Children's Cancer Hospital 57357 Egypt," Sarcoma, vol. 2013, Article ID 439213, 7 pages, 2013. 


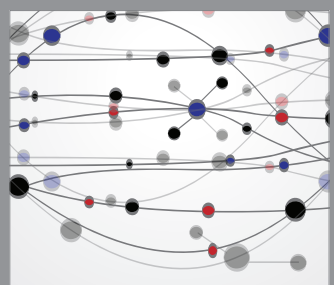

The Scientific World Journal
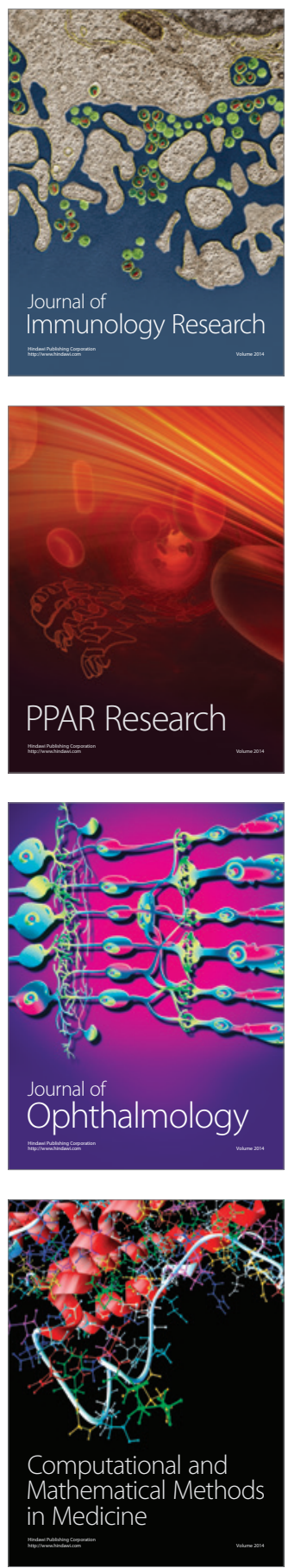

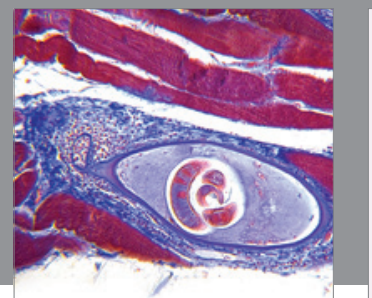

Gastroenterology

Research and Practice
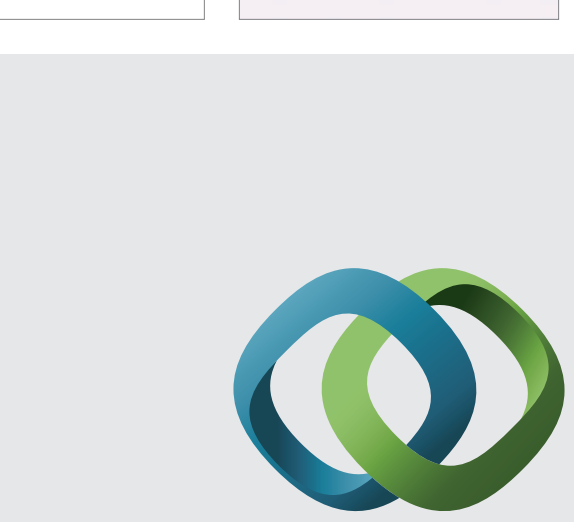

\section{Hindawi}

Submit your manuscripts at

http://www.hindawi.com
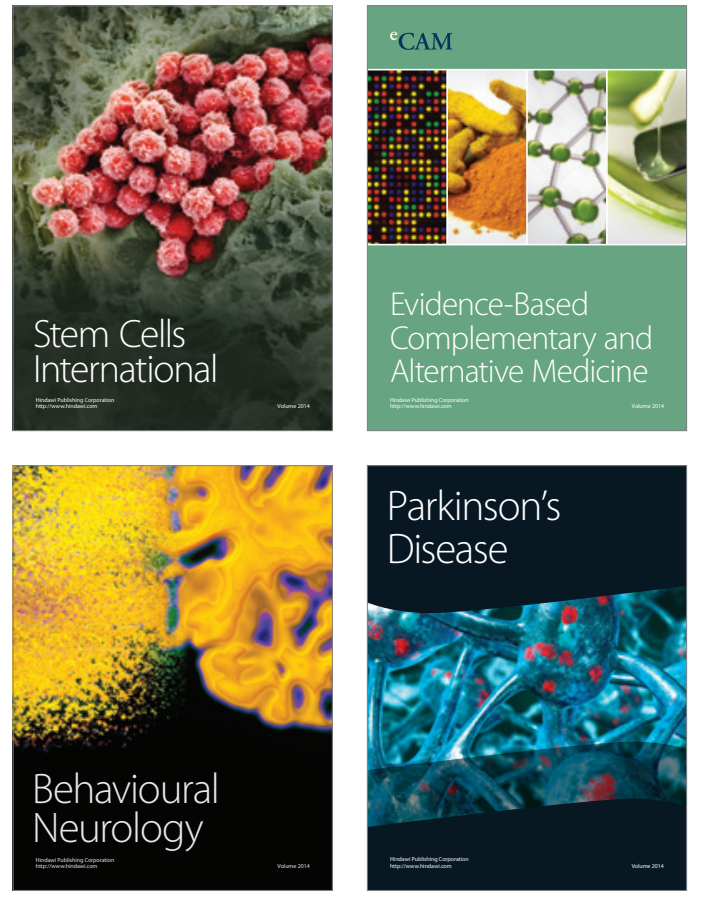
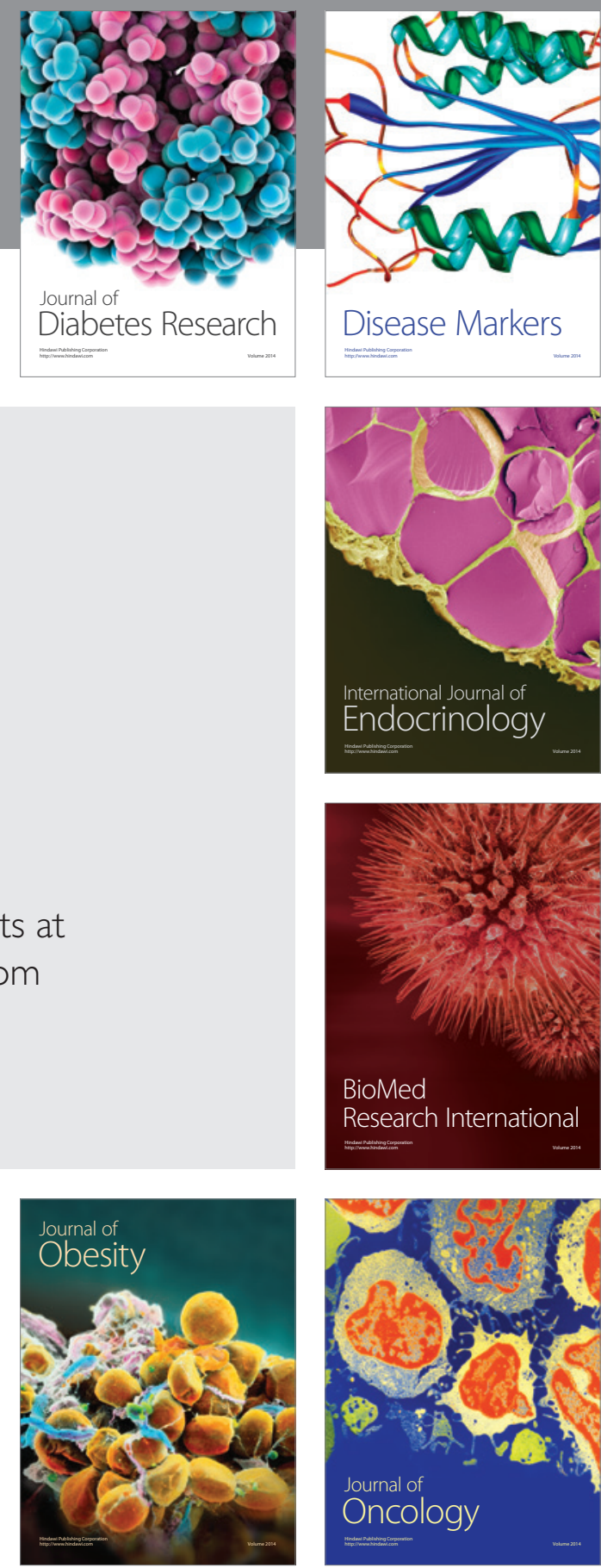

Disease Markers
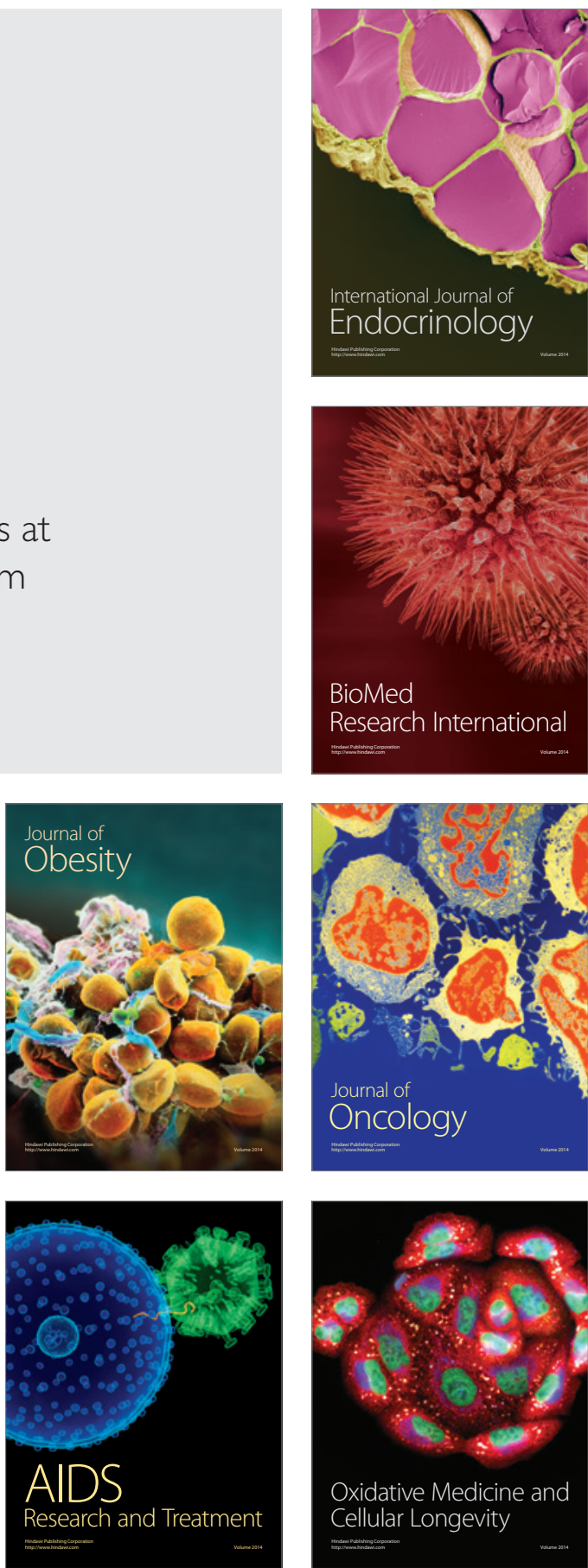